\title{
Implementing optimization of PID controller for DC motor speed control
}

\author{
Yasir G. Rashid ${ }^{1}$, Ahmed Mohammed Abdul Hussain ${ }^{2}$ \\ ${ }^{1}$ Department of Electronic Engineering, College of Engineering, University of Diyala, Diyala, Iraq \\ ${ }^{2}$ Department of Electrical Engineering, College of Engineering, University of Baghdad, Baghdad, Iraq
}

\section{Article Info \\ Article history: \\ Received Mar 4, 2021 \\ Revised May 1, 2021 \\ Accepted May 5, 2021}

Keywords:

DC motor

Genetic algorithm

MATALB PID tunner app

Modified Ziegler-Nichols tuning

PID controller

\begin{abstract}
The point of this paper presents an optimization technique which is flexible and quick tuning by using a genetic algorithm (GA) to obtain the optimum proportional-integral-derivative (PID) parameters for speed control of a separately excited DC motor as a benchmark for performance analysis. The optimization method is used for searching for the proper value of PID parameters. The speed controller of DC motor using PID tuning methods includes three types: MATALB PID tunner app., modified Ziegler-Nichols method and genetic algorithm (GA). PID controller parameters (Kp, Ki and $\mathrm{Kd}$ ) will be obtained by GA to produce optimal performance for the DC motor control system. Simulation results indicate that the tuning method of PID by using a genetic algorithm is shown to create the finest result in system performance such as settling time, rise time, percentage of overshoot and steady state error. The MATLAB/Simulink software is used to model and simulate the proposed DC motor controller system.
\end{abstract}

This is an open access article under the CC BY-SA license.

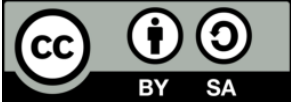

\section{Corresponding Author:}

Yasir G. Rashid

Department of Electronic Engineering, College of Engineering

University of Diyala

Baqubah, Diyala, Iraq

Email: yasserghazee_enge@uodiyala.edu.iq

\section{INTRODUCTION}

DC Motor is broadly used in industrial applications such as steel rolling mills, electric cranes, robotic manipulators and electric vehicles, because of its precise, low cost, wide, simple and easiest to control [1], [2]. Generally, DC motor control system must have high performance such as load regulation response and good dynamic speed command tracking. To achieve high performance for a DC motor control system, optimal PID controller parameters are required, which traditional PID cannot provide, soft computation has been used widely in the last two decades. El-Deen, Mahmoud, and El-Sawi [3] present a soft computing technique that uses a genetic algorithm (GA) to decide the optimal parameters of PID controllers for a DC motor as a benchmark for performance evaluation. The proposed genetic algorithm (GA) is compared to the active set optimization algorithm (ASOA) in this paper. Agarwal et al. [4], compares and analyzes the robustness of as gray wolf-optimized, a FOPID scheme is applied to a fractional-order proportional-integral-derivative (FOPID) on PID controller for dc motor speed control. Based on the genetic algorithm [5], generates an optimally engineered brushless DC motor speed control controller (GA). A PID controller for BLDC motor control device employs the integral squared error (ISE) and integral absolute error (IAE) error criterion. In this paper, a genetic algorithm (GA) optimization strategy for adjusting PID tuning parameters for a separately excited DC motor speed control is proposed. It is critical to obtain the best solution so that the controller has the fastest and most stable response time.Some important advantages of 
using a PID-genetic algorithm can be generalized as faster response time, smaller overshoot, reduced steady state error, reduced oscillations and improved output disturbance rejection [6]-[8]. To achieve the results obtained by the PID-genetic algorithm, compared it with the MATALB PID tunner app. and the modified Ziegler-Nichols (MZN) method. The main goal of this work is to reduce settling time, overshoot, steady-state error, and velocity gain by using a PID controller, which is a generic feedback controller.

\section{DC MOTOR MATHEMATICAL MODEL}

The DC motor that will be studied in this paper is of the separately excited (SEDC) type, and focusing on speed control of DC motor. The schematic of the SEDC motor is shown in Figure 1 [9]-[11].

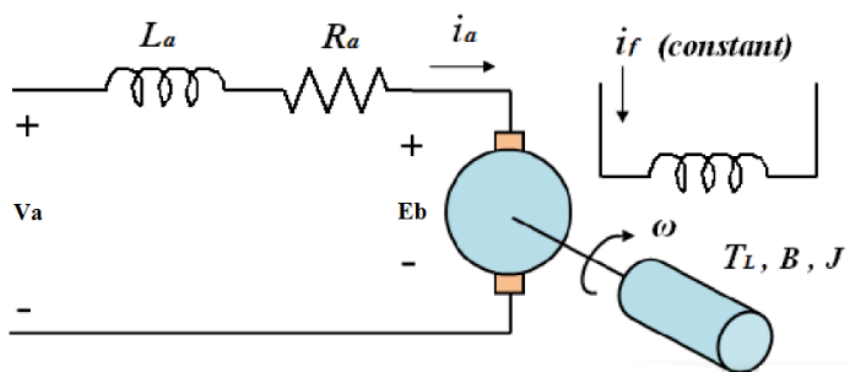

Figure 1. The schematic diagram of SEDC motor

Using the Kirchhoff's law, we can get the following equation obtained:

$$
\begin{aligned}
& \mathrm{V}_{\mathrm{a}}=\mathrm{I}_{\mathrm{a}} \mathrm{R}_{\mathrm{a}}+\mathrm{L}_{\mathrm{a}} \frac{\mathrm{dI}_{\mathrm{a}}}{\mathrm{dt}}+\mathrm{E}_{\mathrm{b}} \\
& \mathrm{E}_{\mathrm{b}}=\mathrm{K}_{\mathrm{b}} \omega \mathrm{I}_{\mathrm{f}} \\
& \mathrm{T}=\mathrm{K}_{\mathrm{t}} \mathrm{I}_{\mathrm{a}} \mathrm{I}_{\mathrm{f}} \\
& \mathrm{T}=\mathrm{J} \frac{\mathrm{d}_{\omega}}{\mathrm{dt}}+\mathrm{B}_{\omega}+\mathrm{T}_{\mathrm{L}}
\end{aligned}
$$

where:

$L_{a}=$ armature inductance $(\mathrm{H})$

$R_{a}=$ armature resistance $(\Omega)$

$V_{a}=$ armature voltage $(\mathrm{V})$

$\mathrm{E}_{\mathrm{b}}=$ back electromotive force (e.m.f.) (V)

ia $=$ armature current $(\mathrm{A})$

$\mathrm{T}_{\mathrm{L}}=$ Load torque $(\mathrm{Nm})$

$\mathrm{B}_{\mathrm{m}}=$ Viscous friction coefficient $(\mathrm{Nms} / \mathrm{rad})$

if $=$ Field current $(\mathrm{A})$

$\mathrm{J}=$ Rotor inertia $\left(\mathrm{kgm}^{2}\right)$

$K_{t}=$ Torque constant $(\mathrm{Nm}-\mathrm{s} / \mathrm{rad})$

$K_{b}=$ Back emf constant (Vs/rad)

The Transfer function T.F of the armature-controlled DC motor given by (5). Block diagram expressed in (6) is following in Figure 2. The DC motor test model parameters for this study are given in Table 1. now, the D.C. motor can be represented by T.F shown in (6).

$$
\begin{aligned}
& \frac{\omega(s)}{V_{a}(s)}=\frac{K_{t}}{\left(J s+B_{m}\right)\left(R_{a}+L_{a} s\right)+K_{t} K_{b}} \\
& \frac{\omega(s)}{V_{a}(s)}=\frac{K_{t}}{\left(L_{a} J\right) s^{2}+\left(R_{a} J+L_{a} B_{m}\right) s+\left(R_{a} B_{m}+K_{t} K_{b}\right)}
\end{aligned}
$$




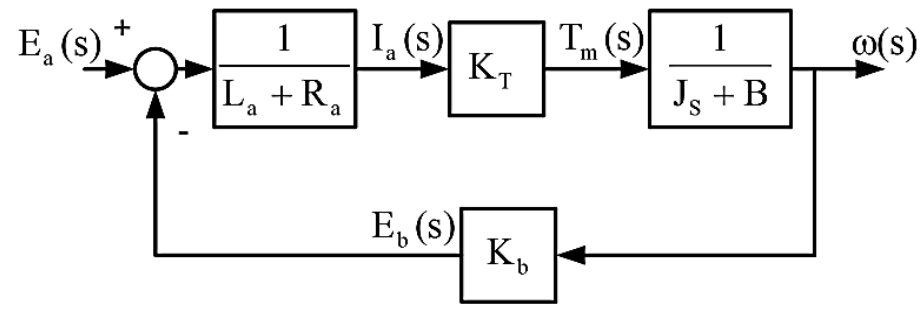

Figure 2. DC Motor Block Diagram

Table 1. Implementation parameters of DC motor [12]

\begin{tabular}{ll}
\hline \multicolumn{1}{c}{ Parameters } & \multicolumn{1}{c}{ Value } \\
\hline Armature inductance $($ Henry $)$ & $\mathrm{L}=0.1215 \mathrm{H}$ \\
Armature resistance $(\mathrm{ohm})$ & $\mathrm{R}=11.2 \Omega$ \\
Rotor inertia $\left(\mathrm{kg} \mathrm{m}^{2}\right)$ & $\mathrm{J}_{\mathrm{m}}=0.02215 \mathrm{~kg}-\mathrm{m}^{2}$ \\
Viscous friction coefficient $\left(\mathrm{N}_{\mathrm{m}} \mathrm{s} / \mathrm{rad}\right)$ & $\mathrm{B}_{\mathrm{m}}=0.002953 \mathrm{~N}_{\mathrm{m}}-\mathrm{s} / \mathrm{rad}$ \\
Motor torque constant $(\mathrm{Nm} / \mathrm{A})$ & $\mathrm{K}_{\mathrm{t}}=1.28 \mathrm{Nm} / \mathrm{A}$ \\
Back emf constant $(\mathrm{V} \mathrm{s} / \mathrm{rad})$ & $\mathrm{K}_{\mathrm{b}}=1.28 \mathrm{~V} \mathrm{~s} / \mathrm{rad}$ \\
Speed & $1500 \mathrm{rpm}$ \\
\hline
\end{tabular}

Thus, the final of T.F is shown in (7).

$\frac{\mathrm{w}(\mathrm{s})}{\mathrm{V}_{\mathrm{a}}(\mathrm{s})}=\frac{1.28}{0.0027 \mathrm{~s}^{2}+0.2481 \mathrm{~s}+1.671}$

\section{PID CONTROLLER}

The proportional-integral-derivative (PID) controller is simple to use and set up, and it is widely used in industrial applications for speed control of dc motors due to its proper control performance and lack of complexity in design [8], [13], [14]. The PID controller form is shown in (8).

$$
\mathrm{G}(\mathrm{s})=\mathrm{K}_{\mathrm{p}}+\frac{\mathrm{K}_{\mathrm{i}}}{\mathrm{s}}+\mathrm{K}_{\mathrm{d}} \mathrm{s}
$$

Where $G(s)$ is the transfer function of PID, $K_{p}, K_{i}$ and $K_{d}$ indicate parameter gainof PID. To improve the performance of any system, there must be proper controller tuning. The setting of the proper parameter value of a controller indicates tuning it. The response of the system becomes unstable and poor, if improper value of gain parameters of a controller is used [15], [16]. Therefore, implementation of PID Tuning is critical to the controller tuning suitable to induce the favored response. Figure 3 illustrates the speed control system for DC motor using a PID controller. Tuning of PID control can be done by many methods. This paper discusses three methods that will be used:

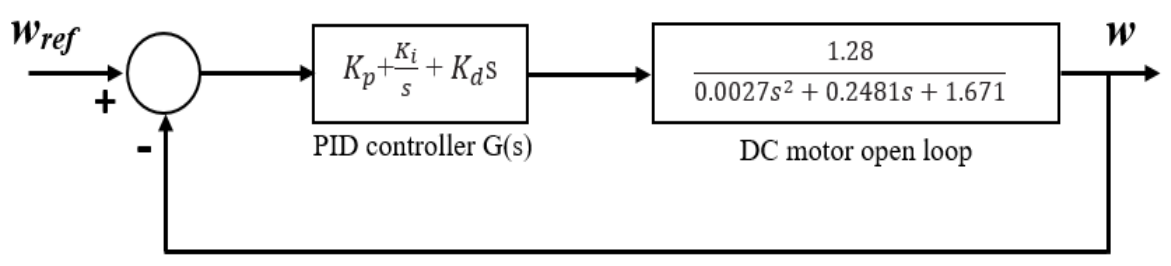

Figure 3. A PID control DC motor speed system

\subsection{MATALB PID tunner app}

By utilizing PID Tuner Application in MATALB R2018a software will obtain gain parameters of PID controller $\mathrm{Kp}=7.632, \mathrm{Ki}=95.733, \mathrm{Kd}=0.0383$ and $\mathrm{N}=382.998$. Figure 4 depicts the response of the DC moror trail and error, as well as the time characteristics. [17]-[19]. 


\subsection{Modified Ziegler-Nichols method}

Depending on the chien - hrones - reswick (CHR) algorithm has been obtained. The modified Ziegler-Nichols (MZN) tuning focuses on disturbance rejection. In addition, response and overshoot can accommodate one of the qualitative specifications The MZN method is more powerful compared to the classical Ziegler-Nichols tuning, the time constant $\mathrm{T}$ of the plant will be used. The MZN tuning formulas are given in Table 2 [20]-[21]. From response curve of T.F in (7) as shown in Figure 5 can be obtained the parameters $a, L$ and $\mathrm{T}, \mathrm{a}=0.0343, \mathrm{~L}=0.0077, \mathrm{~T}=0.2259$. We will get: $\mathrm{K}_{\mathrm{p}}=27.7, \mathrm{~K}_{\mathrm{i}}=\mathrm{K}_{\mathrm{p}} / \mathrm{T}_{\mathrm{i}}=87.586$ and $\mathrm{K}_{\mathrm{d}}=\mathrm{K}_{\mathrm{p}} * \mathrm{~T}_{\mathrm{d}}=0.1002$

Table 2. MZN tuning formulas [19]

\begin{tabular}{cccc}
\hline Controller Type & $\mathrm{K}_{\mathrm{p}}$ & $\mathrm{T}_{\mathrm{i}}$ & $\mathrm{T}_{\mathrm{d}}$ \\
\hline $\mathrm{P}$ & $0.7 / \mathrm{a}$ & & \\
PI & $0.6 / \mathrm{a}$ & $\mathrm{T}$ & \\
PID & $0.95 / \mathrm{a}$ & $1.4 \mathrm{~T}$ & $0.47 \mathrm{~L}$ \\
\hline
\end{tabular}

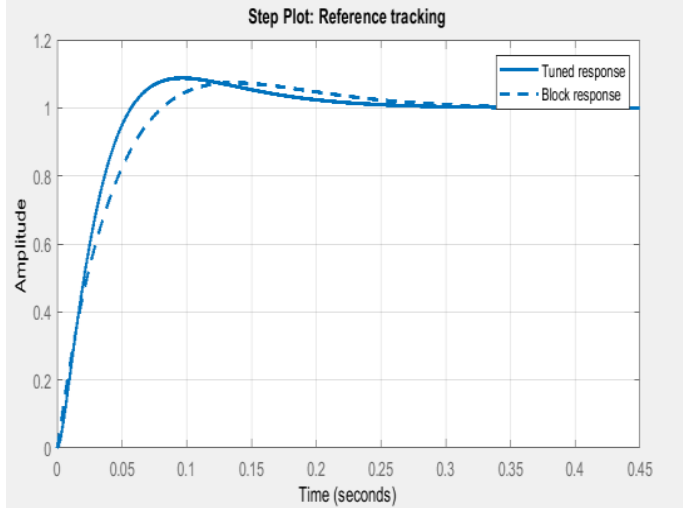

Figure 4. Response of PID tunner app.for DC motor

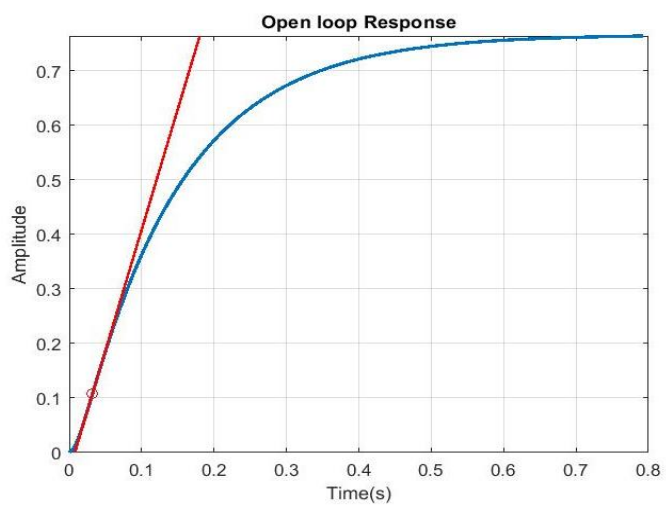

Figure 5. Response curve for MZN

\subsection{Genetic algorithm for PID tuning}

A genetic algorithm is an optimization technique which is an offshoot of natural selection applied to the effect of creating diversity [3]. The starting population contains the number of chromosomes, which are used as problem-solving tools, which are then tested according to their ability to execute the solution. Depending on the fitness of each person, three common processes are performed: selection, crossover, and mutation [22], [23]. Once these three simple operations are applied, new individuals can result in better solutions.

The parameters of population size, crossover rate $(\mathrm{Pc})$, mutation rate $(\mathrm{Pm})$ and the number of generations are the starting points for GA. By sequentially setting the PID parameters, kp, ki, and $\mathrm{kd}$, the population is encoded in binary strings defined as the way that it is The fitness of each chromosome is calculated by taking its two-dimensional strings and transforming them into real values, and replacing them with objective (fitness) function. In this study, we will be using an optimization tool in MATLAB [24], [25]. The GA parameters in this study are shown in Table 3. As illustrated in Figure 6, the GA Step Flowchart shows.

Table 3. Parameter setting of genetic algorithm

\begin{tabular}{lc}
\hline \multicolumn{1}{c}{ Parameter } & Value \\
\hline Lower bound [Kp Ki Kd] & {$\left[\begin{array}{lll}00 & 0\end{array}\right]$} \\
Upper bound [Kp Ki Kd] & {$[100505]$} \\
Populations & 20 \\
Generations G & 80 \\
Population type & Double vector \\
Crossover rate $\mathrm{Pc}$ & 0.8 \\
Mutation rate $\mathrm{P}_{\mathrm{m}}$ & 0.01 \\
Elite count & 5 \\
Selection function & Stochastic uniform \\
\hline
\end{tabular}




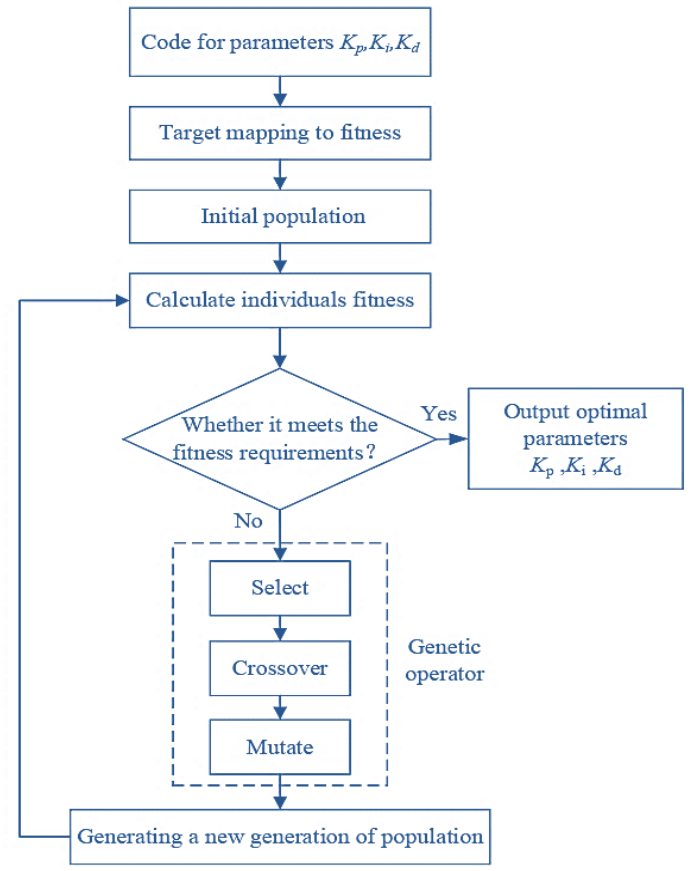

Figure 6. Flowchart for optimal PID tuning based on genetic algorithm [25]

\section{SIMULATION RESULTS}

Figure 7 shows speed control of the DC motor system in Matlab Simulink for various PID tuning methods. In this simulation takes various cases: case i): no-load operation. (at $\mathrm{t}=1 \mathrm{~s}$ ); case ii): full-load operation (at $\mathrm{t}=3 \mathrm{~s}$ ) $\mathrm{TL}=300 \mathrm{Nm}$; case iii): change rotation speed.(at $\mathrm{t}=5 \mathrm{~s}$ ). As shown in Figures 8 (MATALB PID tunner app.) and 9 (MZN), compared to Figure 10 (PID-genetic algorithm) tuning method control with conventional PID methods within the desired speed of $\mathrm{N}=1500 \mathrm{rpm}$, At $\mathrm{t}=1 \mathrm{~s}$, the motor's speed response curve reaches a steady state in a short period of time with no overshoot; at $t=3 \mathrm{~s}$, when the motor is running at full load, the speed response curve decreases slightly and returns to the desired speed more quickly. The system shows great dynamic characteristics and the robustness is greatly improved. Figure 11 shows the comparison of the speed response curve of a motor by using various tuning methods of PID controller, as it can be seen that the performance of each method is different in settling time Ts, rise time $\mathrm{Tr}$ and peak overshoot Mp. PID tuning produces a slower response but has a lower percentage of overshoot than modified Ziegler-Nichols tuning.The genetic algorithm tuning method provides better response compared with conventional methods. In Table 4 shows the performance of each method.

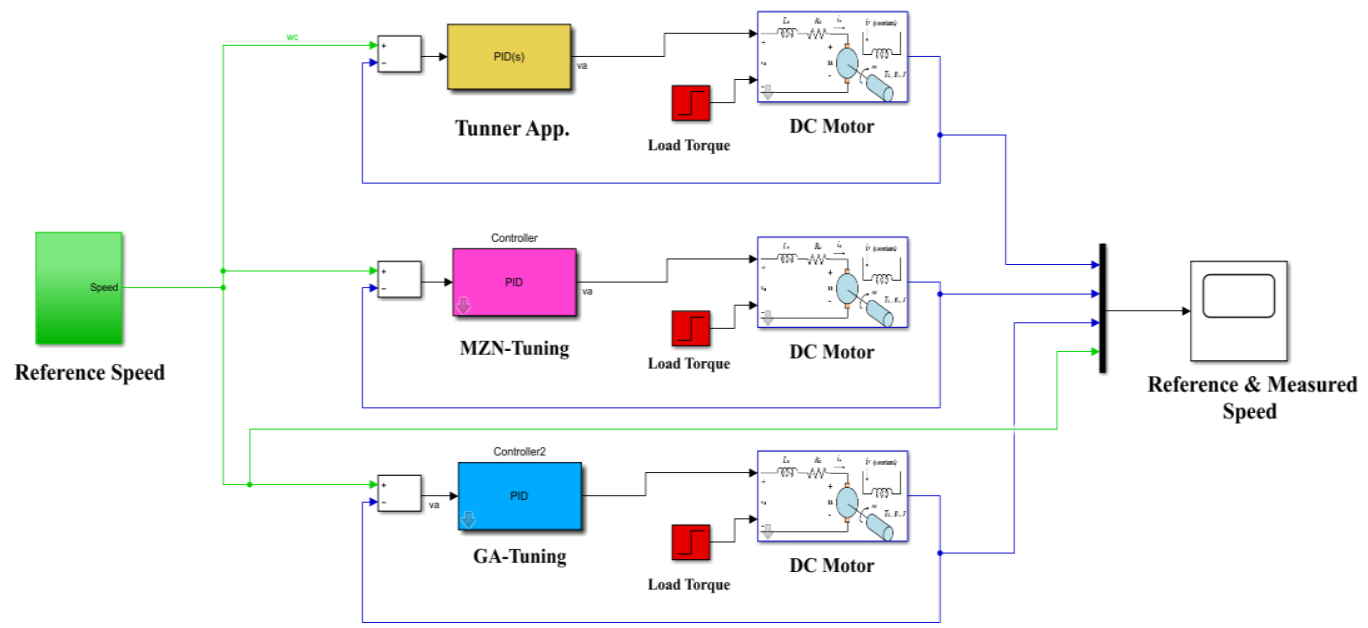

Figure 7. Simulink model of various PID tuning methods 
Table 4. Comparison between the performance of various PID tuning methods

\begin{tabular}{lcccc}
\hline Tuning method & $\mathrm{M}_{\mathrm{p}} \%$ & $\mathrm{~T}_{\mathrm{r}}(\mathrm{s})$ & $\mathrm{T}_{\mathrm{s}}(\mathrm{s})$ & Steady state error \\
\hline Tuner Adds & 18.37 & 0.15 & 1.43 & 0 \\
MZN & 9.65 & 0.12 & 1.26 & 0 \\
$\mathrm{GA}$ & 0 & 0.056 & 1.12 & 0 \\
\hline
\end{tabular}

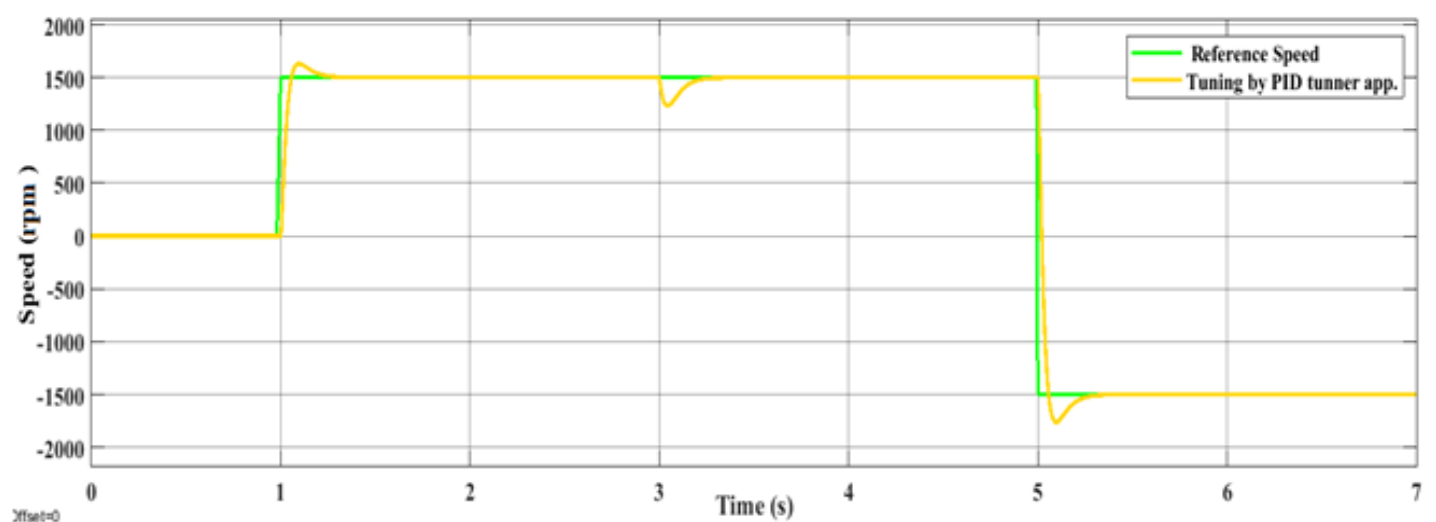

Figure 8. Speed versus time with reference speed of PID controller based on PID tunner app

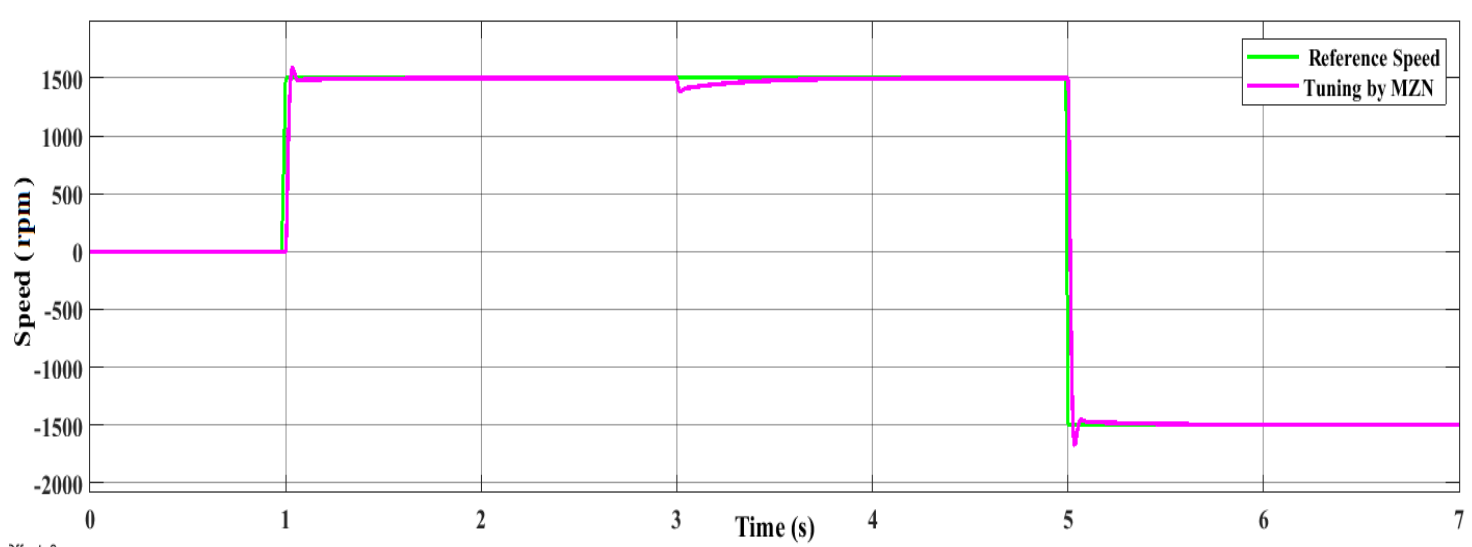

Figure 9. Speed versus time with reference speed of PID controller based on MZN

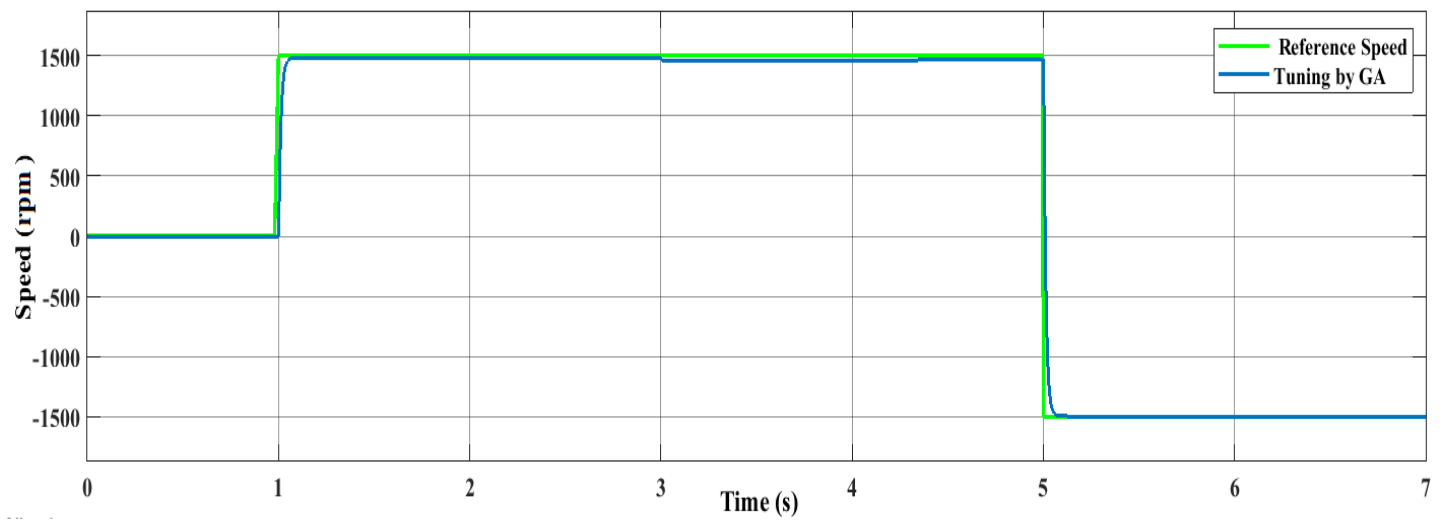

Figure 10. Speed versus time with reference speed of PID controller based on GA 


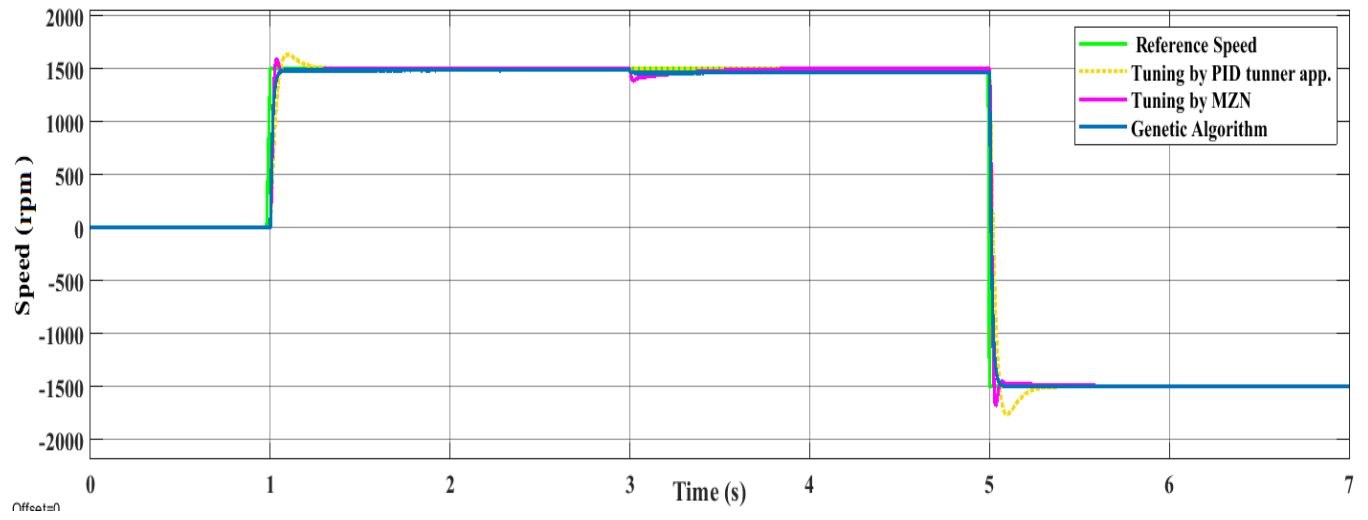

Figure 11. Speed versus time with reference speed of PID controller based on Z-N, tunner app. and GA

\section{CONCLUSION}

A DC motor speed control using genetic algorithm optimization to determine the proper value gain of PID parameter is presented in this paper. As well, compares its performance with conventional methods MATALB PID tunner app. and Modified Ziegler-Nichols. The results obtained by PID-genetic algorithm compared to other methods, show a high-performance response for DC motor such as less settling time, less rise time, reduced steady state error and no overshoot rate. The PID-GA tuning method as a speed controller for the DC motor is a very effective method. The proposed system's performance is improved and reaches the required requirements.

\section{REFERENCES}

[1] D. Somwanshi, M. Bundele, G. Kumar, and G. Parashar, "Comparison of fuzzy-PID and PID controller for speed control of DC motor using LabVIEW," Procedia Computer Science, vol. 152, pp. 252-260, 2019, doi: 10.1016/j.procs.2019.05.019.

[2] S. Ekinci, B. Hekimoğlu, and D. Izci, "Opposition based Henry gas solubility optimization as a novel algorithm for PID control of DC motor," Engineering Science and Technology, an International Journal, vol. 24, no. 2, 2021, doi: $10.1016 /$ j.jestch.2020.08.011.

[3] T. El-Deen, A. A. H. Mahmoud, and A. R. El-Sawi, "Optimal PID tuning for DC motor speed controller based on genetic algorithm," Int. Rev. Autom. Control, vol. 8, no. 1, pp. 80-85, 2015, doi: 10.15866/ireaco.v8i1.4839.

[4] J. Agarwal, G. Parmar, R. Gupta, and A. Sikander, "Analysis of grey wolf optimizer based fractional order PID controller in speed control of DC motor," Microsystem Technologies, vol. 24, no. 12, pp. 4997-5006, 2018, doi: 10.1007/s00542-018-3920-4.

[5] M. A. Ibrahim, A. K. Mahmood, and N. S. Sultan, "Optimal PID controller of a brushless dc motor using genetic algorithm," International Journal of Power Electronics and Drive System (IJPEDS), vol. 10, no. 2, p. 822, 2019, doi: 10.11591/ijpeds.v10.i2.pp822-830.

[6] R. V. Jain, M. V. Aware, and A. S. Junghare, "Tuning of Fractional Order PID controller using particle swarm optimization technique for DC motor speed control," 2016 IEEE 1st International Conference on Power Electronics, Intelligent Control and Energy Systems (ICPEICES), 2016, pp. 1-4, doi: 10.1109/ICPEICES.2016.7853070.

[7] L. Syafaah, Widianto, I. Pakaya, D. Suhardi, and M. Irfan, "PID designs using DE and PSO algorithms for damping oscillations in a DC motor speed," 4th International Conference on Electrical Engineering, Computer Science and Informatics (EECSI), vol. 2017-December, no. September, 2017, pp. 19-21, doi: 10.1109/EECSI.2017.8239138.

[8] G. A. Salman, A. S. Jafar, and A. I. Ismael, "Application of artificial intelligence techniques for LFC and AVR systems using PID controller," International Journal of Power Electronics and Drive Systems (IJPEDS), vol. 10, no. 3, pp. 1694, 2019, doi: 10.11591/ijpeds.v10.i3.pp1694-1704.

[9] K. Mishra, V. K. Tiwari, R. Kumar, and T. Verma, "Speed Control of DC Motor Using Artificial Bee Colony Optimization Technique," International Conference on Control, Automation, Robotics and Embedded Systems (CARE), vol. 1, no. 3, 2013, pp. 68-75, doi: 10.13189/ujeee.2013.010302.

[10] G. Farahani and K. Rahmani, "Speed control of a separately excited DC motor using new proposed fuzzy neural algorithm based on FOPID controller," Journal of Control, Automation and Electrical Systems, vol. 30, no. 5, pp. 728-740, 2019, doi: 10.1007/s40313-019-00485-8.

[11] Abdulameer, M. Sulaiman, M. S. M. Aras, and D. Saleem, "Tuning methods of PID controller for DC motor speed control," Indonesian Journal of Electrical Engineering and Computer Science (IJEECS), vol. 3, no. 2, pp. 343-349, 2016, doi:10.11591/ijeecs.v3.i2.pp343-349.

[12] S. K. Suman and V. K. Giri, "Speed control of DC motor using optimization techniques based PID Controller," in 2016 IEEE International Conference on Engineering and Technology (ICETECH), 2016, pp. 581-587, doi: 10.1109/ICETECH.2016.7569318. 
[13] D. Pathak, G. Sagar, and P. Gaur, "An Application of Intelligent Non-linear Discrete-PID Controller for MPPT of PV System," Procedia Computer Science, vol. 167, no. 2019, pp. 1574-1583, 2020, doi: 10.1016/j.procs.2020.03.368.

[14] G. A. Salman, H. I. Hussein, and M. S. Hasan, "Enhancement The Dynamic Stability of The Iraq's Power Station Using PID Controller Optimized by FA and PSO Based on Different Objective Functions," Elektrotehniski Vestnik, vol. 85, no. 1/2, pp. 42-48, 2018.

[15] S. Tiwari, A. Bhatt, A. C. Unni, J. G. Singh, and W. Ongsakul, "Control of DC motor using genetic algorithm based pid controller," in 2018 International Conference and Utility Exhibition on Green Energy for Sustainable Development (ICUE), 2018, pp. 1-6, doi: 10.23919/ICUE-GESD.2018.8635662.

[16] W.-J. Tang, Z.-T. Liu, and Q. Wang, "Dc motor speed control based on system identification and pid auto tuning," in 2017 36th Chinese Control Conference (CCC), 2017, pp. 6420-6423, doi: 10.23919/ChiCC.2017.8028376.

[17] C. Robles-Algarín, O. Rodríguez, and A. Ospino, "Evaluation of non-parametric identification techniques in second order models plus dead time," International Journal of Electrical and Computer Engineering (IJECE), vol. 10, no. 6, pp. 6340-6348, 2020, doi: 10.11591/ijece.v10i6.pp6340-6348.

[18] S. I. Khather and M. A. Ibrahim, "Modeling and simulation of SEPIC controlled converter using PID controller," International Journal of Power Electronics and Drive Systems (IJPEDS), vol. 11, no. 2, pp. 833-843, 2020, doi: 10.11591/ijpeds.v11.i2.pp833-843.

[19] P. M. Meshram and R. G. Kanojiya, "Tuning of PID controller using Ziegler-Nichols method for speed control of DC motor," in IEEE-international conference on advances in engineering, science and management (ICAESM2012), pp. 117-122, 2012.

[20] S. A. Bhatti, S. A. Malik, and A. Daraz, "Comparison of P-I and I-P controller by using Ziegler-Nichols tuning method for speed control of DC motor," International Conference on Intelligent Systems Engineering (ICISE) 2016, 2016, pp. 330-334, doi: 10.1109/INTELSE.2016.7475144.

[21] M. Kushwah and A. Patra, "PID Controller Tuning using Ziegler-Nichols Method for Speed Control of DC Motor," International Journal of Scientific Engineering and Technology Research, vol. 3, no. 13, pp. 2924-2929, 2014.

[22] W. N. A.-D. Abed, A. H. Saleh, and A. S. Hameed, "Speed Control of PMDCM Based GA and DS Techniques," International Journal of Power Electronics and Drive Systems (IJPEDS), vol. 9, no. 4, p. 1467, 2018, doi:10.11591/ijpeds.v9n4.pp1467-1475.

[23] M. M. Gani, M. S. Islam, and M. A. Ullah, "Optimal PID tuning for controlling the temperature of electric furnace by genetic algorithm," SN Applied Sciences, vol. 1, no. 8, pp. 1-8, 2019, doi: 10.1007/s42452-019-0929-y.

[24] G. Mantri and N. R. Kulkarni, "Design and optimization of PID controller using genetic algorithm," International Journal of Research in Engineering and Technology, vol. 2, no. 6, pp. 926-930, 2013, doi: 10.15623/IJRET.2013.0206002.

[25] M. S. Amiri, M. F. Ibrahim, and R. Ramli, "Optimal parameter estimation for a DC motor using genetic algorithm," International Journal of Power Electronics and Drive Systems (IJPEDS), vol. 11, no. 2, p. 1047, 2020, doi: 10.11591/ijpeds.v11.i2.pp1047-105.

\section{BIOGRAPHIES OF AUTHORS}
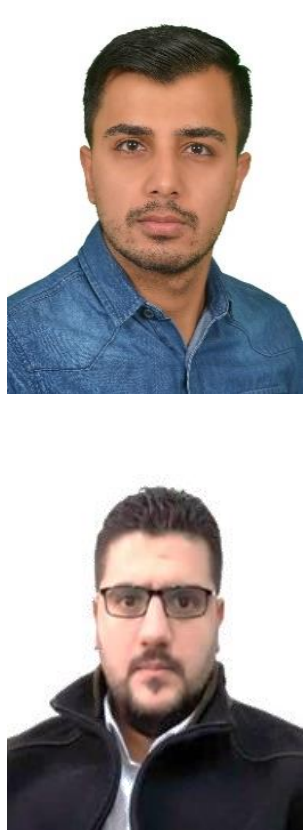

Yasir Ghazi Rashid was born in Ammaan/Jordan, 1991. He works at Diyala university, college of engineering, Electronic Engineering Department. He received a BS.c degree in electrical power and machines from Diyala University in 2013, MSc degree in electrical engineering/power and machines from Baghdad University in 2019. His current research activities are in the fields of renewable energy, wind power, optimization techniques, optimal power flow, drive machine and power system operation and control.

Email: yasserghazee_enge@uodiyala.edu.iq

Ahmed Mohammed Abdul Hussain obtained a bachelor's degree in electrical engineering from Baghdad University in 2010, MSc degree in electrical engineering/power and machines in 2019. Renewable resources, power electronics, electric power, artificial intelligence, control of machinery engineering machinery, and other fields of study are all of interest to researchers. Email: a.aladely@coeng.uobaghdad.edu.iq 